\title{
Comparative analysis of two optical biometry devices: high wavelength swept source OCT versus partial coherence interferometry
}

\author{
Eszter Szalai (i) Adrienne Csutak
}

Received: 16 February 2021 / Accepted: 22 September 2021 / Published online: 11 October 2021

(C) The Author(s) 2021

\begin{abstract}
Purpose To study the reproducibility of measurements performed with a recently developed multimodal high resolution swept source optical coherence tomography (SSOCT) and to make comparisons with a partial coherence interferometry (PCI) biometer.

Methods One hundred and fifty-two eyes of 152 subjects were involved in this study with a mean age of $65.71 \pm 13.86$ years (26-85 years). Anterior surface keratometry $(\mathrm{K})$, anterior chamber depth (ACD), white-to-white (WTW) and axial length (AL) values were recorded by the SSOCT (ANTERION, Heidelberg Engineering Ltd, Germany) and PCI (IOLMaster 500, version 5.5, Carl Zeiss Meditec, Germany). Intraocular lens (IOL) power was calculated based on ANTERION and IOLMaster keratometry values by using five traditional vergence formulas.

Results Anterior surface simulated keratometry values did not differ significantly between the IOLMaster and ANTERION $(P>0.05)$. AL measurements were successful in $95 \%$ of the cases both with the SSOCT and PCI. No significant difference was disclosed between the two instruments $(P=0.229)$. For WTW measurements, a significant difference was observed between the two optical biometers $(P<0.0001)$. The difference between PCI and SSOCT in IOL powers
\end{abstract}

E. Szalai $(\bowtie) \cdot$ A. Csutak

Department of Ophthalmology, University of Pécs Medical School, Rákóczi u. 2, 7623 Pecs, Hungary

e-mail: szalai.eszter@pte.hu was statistically significant for SRK/T, Hoffer and Holladay formulas $(P<0.001)$.

Conclusion Our results implicated an overall good reproducibility of anterior keratometry, AL, ACD and WTW measurements for IOLMaster and ANTERION. The discrepancies between their measurements resulted in significant difference in the calculated IOL power for SRK/T, Hoffer and Holladay formulas, but not for Haigis formula.

Keywords Biometry $\cdot$ Partial coherence interferometry $\cdot$ Reproducibility $\cdot$ Swept source optical coherence tomography

\section{Introduction}

Precise calculation of the intraocular lens (IOL) is of importance in preoperative evaluation of patients with cataract. In planning the IOL power, axial length (AL) and keratometry value $(\mathrm{K})$, as well as anterior chamber depth (ACD), lens thickness (LT), corneal diameter (WTW), are required depending on the applied calculation formula [1]. Partial coherence interferometry (PCI) has been the gold standard for optical biometry since its introduction in autumn 1999 [1, 2]. However, traditional PCI-based devices have not been able to provide data on the posterior corneal surface, thickness of crystalline lens and corneal pachymetry. 
Also, they could have difficulties in measuring dense cataracts due to the use of $780 \mathrm{~nm}$ wavelength laser diode infrared light. Novel third-generation optical biometers that employ swept source optical coherence tomography (SSOCT) technology include IOLMaster 700 (Carl Zeiss Meditec AG, Jena, Germany), Argos (Movu, Inc., CA, USA), OA-2000 (Tomey, Nagoya, Japan), Eyestar 900 (Haag Streit, Koeniz, Switzerland) and ANTERION (Heidelberg Engineering, Germany). These instruments use longer wavelengths ranging from 1050 to $1300 \mathrm{~nm}$ that allow for less scattering and deeper penetration through opaque media.

Traditional keratometry instruments measure radius of curvature of the paracentral anterior cornea and calculate corneal power using a standard keratometric index. Hypothetically, determination of total corneal power calculated based on both anterior and posterior corneal curvatures should improve the accuracy in IOL power prediction. Anterior segment OCTs can measure both anterior and posterior corneal curvatures with high axial resolution to compute total corneal power.

The aim of this study was to investigate the reproducibility of measurements performed using a recently introduced multimodal high resolution swept source OCT and to make comparisons with a traditional PCI biometer. We also investigated the impact of discrepancy between the two optical biometers on IOL calculation using different traditional formulas.

\section{Materials and methods}

\section{Study design}

Ocular biometry was performed in 152 phakic eyes of 152 patients (98 females, 54 males; 82 right, 70 left eyes) using a newly developed high wavelength swept source anterior segment OCT and PCI (Zeiss IOLMaster version 5.5, Carl Zeiss Meditec AG, Jena, Germany). The mean age was $65.71 \pm 13.86$ years (ranging from 26 to 85 years). All subjects had a negative history of ocular disease (other than refractive errors excluding corneal ectasias), trauma or surgery. The study population included a wide spectrum of disease severity, with the vast majority of patients graded clinically as moderate to advanced lens opacities. Five percent of study patients had intumescent lenses and only $12 \%$ had low grade changes. The local Institutional Review Board approved this study in accordance with the Declaration of Helsinki.

ANTERION ${ }^{\circledR}$ SSOCT employs a $1300 \mathrm{~nm}$ light source and its Cataract App (Heyex Software, Version 2.4.3, Heidelberg Engineering) performs biometry analysis which combines important measurements for preoperative IOL planning including comprehensive corneal assessment, aqueous depth (AQD), lens thickness, WTW and axial length. ACD was calculated by adding the $\mathrm{CCT}$ to the AQD. Comprehensive corneal assessment is achieved by measuring the anterior and posterior cornea and computing multiple maps (anterior and posterior axial curvature, tangential curvature and elevation maps, as well as total corneal power map, anterior and total corneal wave front and pachymetry maps). SSOCT computes total corneal power based on measuring the anterior and posterior corneal surface in a central $3 \mathrm{~mm}$ ring, total $\mathrm{K}$ is defined as the average refractive power of the cornea, derived from the anterior and posterior corneal surfaces. The conversion of anterior radii to keratometry values is performed according to the laws of Gaussian optics using the keratometric index of 1.3375. Anterior axial simulated keratometry values are calculated with the indicated keratometric index for a $3 \mathrm{~mm}$ ring. IOLMaster utilizes PCI to evaluate axial length, based on the Michelson interferometer. Keratometry values of the IOLMaster are obtained from six points reflected off the anterior surface of the central cornea (approximately in a $2.5 \mathrm{~mm}$ diameter). The IOLMaster uses a slit beam of light through the anterior segment of the eye at and the internal software measures the distance between the anterior corneal surface and the anterior crystalline lens surface to calculate ACD [3]. For WTW measurements, the same principle was applied by the IOLMaster.

Biometry measurements by SSOCT and PCI were taken on each eye in random order. Patients were positioned on the forehead and chin rest, and they were instructed to fixate on the built-in fixation light of the instrument. Biometry measurements by SSOCT and PCI were taken on each eye in random order. Anterior segment biometry parameters and instrument-based IOL power calculations were recorded and used for further analysis.

Optical biometry readings of IOLMaster and ANTERION were used to predict the IOL power with 
four paraxial thin lens IOL calculation formulas. The Hoffer Q, Holladay I, Haigis and SRK/T formulas were applied and analyzed [4-6]. For IOLMaster and ANTERION, simulated keratometry of the anterior corneal surface was used. In every case, IOL power calculations were performed using the IOL constants for Acrysof SN60WF (Alcon Laboratories Inc.) (available at http://ocusoft.de/ulib/c1.htm).

\section{Statistical analysis}

Statistical analyses were performed with SPSS (Version 9.0.0) and MedCalc Statistical Software (Version 10.0.2.0). Data were described as mean \pm standard deviation (SD) and 95\% confidence intervals (CI) were also provided. The Kolmogorov-Smirnov test was used to analyze whether our data were normally distributed. To determine the difference between two measurements, Student's $t$-test was applied. The correlation between instruments was calculated by Pearson's correlation test. Bland-Altman plots were created, and the $95 \%$ limits of agreement $(95 \%$ $\mathrm{LoA}=$ mean difference $\pm 1.96 \mathrm{SD}$ of the difference) were determined to compare two methods [7, 8]. To estimate intra-device consistency, intraclass correlation coefficients (ICC) and their 95\% CI were calculated. The results were defined as statistically significant if $P$ value was less than 0.05 .

\section{Results}

All biometry measurements obtained by both devices are summarized in Table 1. Anterior surface simulated keratometry values did not differ significantly between the IOLMaster and ANTERION. High reproducibility was found in $\mathrm{Ks}$ and $\mathrm{Kf}$ values for the two instruments (ICC $=0.951$ and 0.970, respectively). Bland-Altman plots showed low difference with acceptable $95 \%$ LoA for the keratometry values (Fig. 1). Total Kf was $42.94 \pm 7.73 \mathrm{D}(95 \% \mathrm{CI}$ : 41.70-44.19 D), total Ks was $43.51 \pm 6.06$ D (95\% CI: 42.53-44.48 D) measured with SSOCT. Both the total $\mathrm{Kf}$ and total $\mathrm{Ks}$ were lower than the simulated $\mathrm{Kf}$ $(P=0.223)$ and $\mathrm{Ks}$, but the difference (Kf: $-0.74 \pm 7.44 \mathrm{D}$; Ks: $-1.14 \pm 5.91 \mathrm{D})$ was only significant for Ks $(P=0.019)$. The correlation was poor both between simulated $\mathrm{Kf}$ and total $\mathrm{Kf}$ $(r=0.279, P=0.0005)$, and between simulated Ks and total Ks $(r=0.231, P=0.004)$ obtained with SSOCT. The magnitude of anterior surface astigmatism did not differ significantly between the two instruments $(P=0.182)$. Good intra-device consistency was indicated by ICC (0.823) and small difference was obtained between the SSOCT and PCI for anterior surface astigmatism.

Axial length measurements were successful in 95\% of the cases (145/152) both with the SSOCT and PCI; in 3 cases ( $2 \%$ ) neither of the two devices was able to measure AL (Fig. 2). No significant difference was disclosed between the two instruments $(P=0.229)$ and good reproducibility was observed for them in the AL measurements ( $\mathrm{ICC}=0.832$ ). Bland-Altman analysis indicated low difference between the instruments with wide $95 \%$ LoA (Fig. 3).

AQD measured with ANTERION was $2.64 \pm 0.395 \mathrm{~mm}$ (95\% CI: $2.57-2.70 \mathrm{~mm}$ ). ACD measurements were not significantly different between the two instruments $(P=0.880)$. ICC indicated high reproducibility for the instruments $(0.914)$ and the difference was low $(0.002 \pm 0.16 \mathrm{~mm})$ with narrow $95 \%$ LoA.

For WTW measurements, statistically significant difference was observed between the two optical biometers $(P<0.0001)$. The reproducibility of both devices was acceptable (ICC $=0.768$ ) in measuring WTW. Bland-Altman plot showed small difference in WTW values between SSOCT and PCI with narrow 95\% LoA (Fig. 4).

For all IOL calculation formulas, SSOCT using simulated keratometry of the anterior corneal surface resulted in higher IOL power than that for PCI (Fig. 5). The difference between PCI and SSOCT in IOL powers was statistically significant for SRK/T, Hoffer Q and Holladay I formulas ( $P=0.0001-0.0004)$, but not for Haigis formula $(P=0.242)$ (Fig. 5).

\section{Discussion}

Swept source OCT is a recent development of Fourier domain OCT using a tunable laser as a light source [9]. There are several advantages of a swept source OCT technique over the former systems, including short image acquisition time, less motion artifacts, high axial, lateral resolution, deeper tissue penetration, improved safety profile [10]. During biometry, a total 
Table 1 Anterior corneal parameters and biometry values measured with partial coherence interferometry (PCI) and swept source optical coherence tomography (SSOCT)

\begin{tabular}{|c|c|c|c|c|c|c|c|}
\hline & $\mathrm{PCI}^{\mathrm{a}}$ & $\mathrm{SSOCT}^{\mathrm{a}}$ & $P^{*}$ & $r^{\#}$ & $\begin{array}{l}\text { ICC } \\
(95 \% \mathrm{CI})\end{array}$ & $\begin{array}{l}\text { Difference } \\
\text { (SSOCT-PCI) }\end{array}$ & $95 \%$ LoA \\
\hline $\mathrm{Kf}(\mathrm{D})$ & $\begin{array}{l}43.67 \pm 1.60 \\
(43.41-43.92)\end{array}$ & $\begin{array}{l}43.68 \pm 1.67 \\
(43.42-43.95)\end{array}$ & 0.609 & $\begin{array}{l}0.952 \\
(<0.0001)\end{array}$ & $\begin{array}{l}0.951 \\
(0.934-0.965)\end{array}$ & $+0.02 \pm 0.51$ & $\begin{array}{l}-0.98 \\
\text { to }+1.02\end{array}$ \\
\hline Ks (D) & $\begin{array}{l}44.69 \pm 1.67 \\
(44.42-44.96)\end{array}$ & $\begin{array}{l}44.64 \pm 1.697 \\
(44.37-44.92)\end{array}$ & 0.189 & $\begin{array}{l}0.970 \\
(<0.0001)\end{array}$ & $\begin{array}{l}0.970 \\
(0.959-0.978)\end{array}$ & $-0.04 \pm 0.41$ & $\begin{array}{l}-0.86 \\
\text { to }+0.77\end{array}$ \\
\hline $\begin{array}{l}\text { Astigmatism } \\
\text { (D) }\end{array}$ & $\begin{array}{l}1.02 \pm 0.829 \\
(0.88-1.15)\end{array}$ & $\begin{array}{l}0.96 \pm 0.85 \\
(0.83-1.10)\end{array}$ & 0.182 & $\begin{array}{l}0.824 \\
(<0.0001)\end{array}$ & $\begin{array}{l}0.823 \\
(0.764-0.869)\end{array}$ & $-0.06 \pm 0.50$ & $\begin{array}{l}-1.17 \\
\text { to }+0.93\end{array}$ \\
\hline $\begin{array}{l}\text { Cylinder axis } \\
\text { (Degree) }\end{array}$ & $\begin{array}{l}87.72 \pm 60.89 \\
(77.92-97.51)\end{array}$ & $\begin{array}{l}85.97 \pm 45.58 \\
(78.64-93.30)\end{array}$ & 0.776 & $\begin{array}{l}-0.310 \\
(<0.0001)\end{array}$ & $\begin{array}{l}-0.298 \\
(-0.437--0.145)\end{array}$ & $-2.02 \pm 86.73$ & $\begin{array}{l}-172.01 \\
\text { to }+167.97\end{array}$ \\
\hline $\mathrm{AL}(\mathrm{mm})$ & $\begin{array}{l}23.33 \pm 1.25 \\
(23.13-23.54)\end{array}$ & $\begin{array}{l}23.24 \pm 1.12 \\
(23.05-23.42)\end{array}$ & 0.229 & $\begin{array}{l}0.837 \\
(<0.0001)\end{array}$ & $\begin{array}{l}0.832 \\
(0.774-0.877)\end{array}$ & $-0.07 \pm 0.69$ & $\begin{array}{l}-1.43 \\
\text { to }+1.29\end{array}$ \\
\hline $\mathrm{ACD}(\mathrm{mm})$ & $\begin{array}{l}3.19 \pm 0.388 \\
(3.13-3.25)\end{array}$ & $\begin{array}{l}3.18 \pm 0.395 \\
(3.12-3.24)\end{array}$ & 0.880 & $\begin{array}{l}0.914 \\
(<0.0001)\end{array}$ & $\begin{array}{l}0.914 \\
(0.882-0.937)\end{array}$ & $-0.002 \pm 0.16$ & $\begin{array}{l}-0.32 \\
\text { to }+0.32\end{array}$ \\
\hline WTW (mm) & $\begin{array}{l}12.00 \pm 0.46 \\
(11.92-12.08)\end{array}$ & $\begin{array}{l}11.69 \pm 0.45 \\
(11.61-11.76)\end{array}$ & $<0.0001$ & $\begin{array}{l}0.768 \\
(<0.0001)\end{array}$ & $\begin{array}{l}0.768 \\
(0.690-0.828)\end{array}$ & $-0.32 \pm 0.31$ & $\begin{array}{l}-0.93 \\
\text { to }+0.30\end{array}$ \\
\hline
\end{tabular}

LoA limits of agreement

*Paired $t$-test (PCI versus SSOCT)

\#Pearson's correlation coefficient

${ }^{\mathrm{a}}$ Mean $\pm \mathrm{SD}(95 \%$ confidence interval)
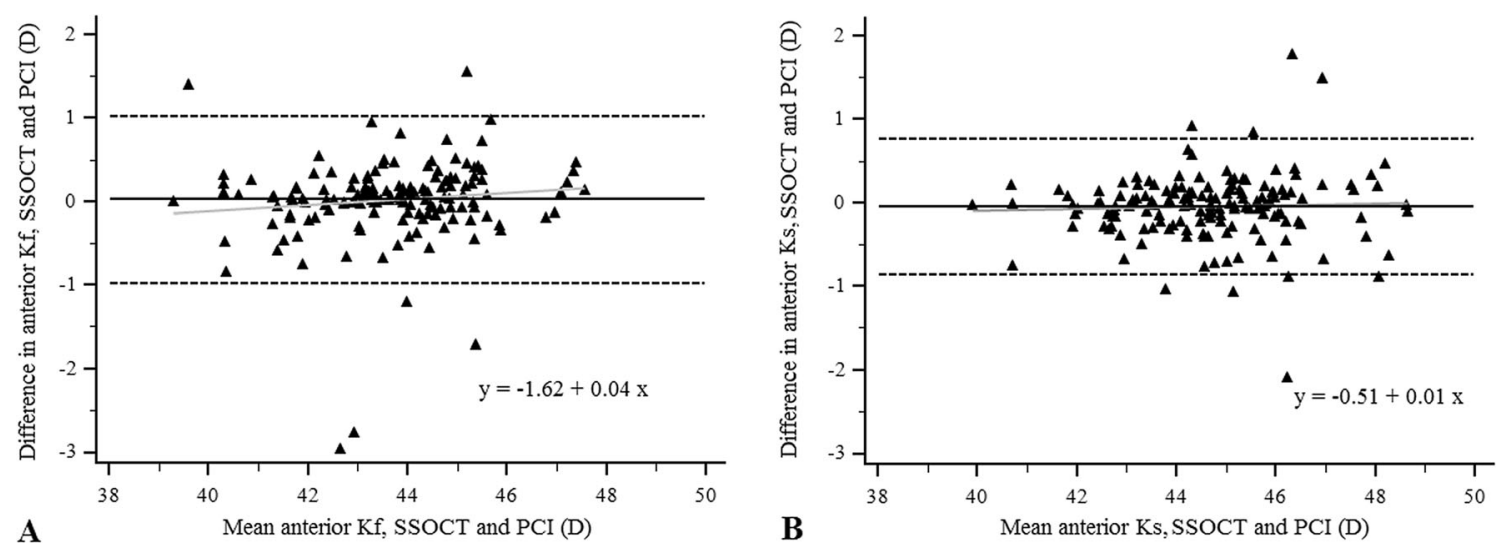

Fig. 1 Bland-Altman plots of the difference in anterior flat keratometry (Kf) and in anterior steep keratometry (Ks) measurements between ANTERION (SSOCT) and IOLMaster (PCI) against their mean (A, B, respectively)

of 65 radial B-scans (256 A-scans per B-scan) are acquired using the ANTERION Cornea App and one anterior segment biometry evaluation (768 A-scans per B-scan) is performed in the Cataract App. Although not able to quantify the severity of cataract, recent SSOCT devices are able to provide a subjective estimation of the severity of opacities and visualization of the crystalline lens.

ANTERION is capable of performing a comprehensive corneal analysis and the result is integrated in its Cataract App. In this study, anterior surface simulated keratometry values did not differ significantly between the IOLMaster and ANTERION. Yang 


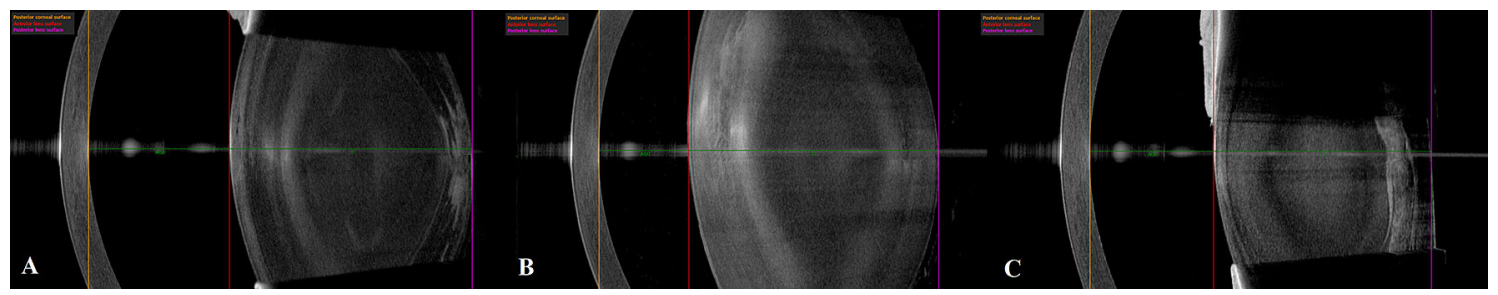

Fig. 2 Visualization of the severity of lens opacities with the ANTERION Cataract App. a Posterior subcapsular cataract and dense nuclear opacities, neither ANTERION nor IOLMaster was able to perform axial length (AL) measurement. b Anterior

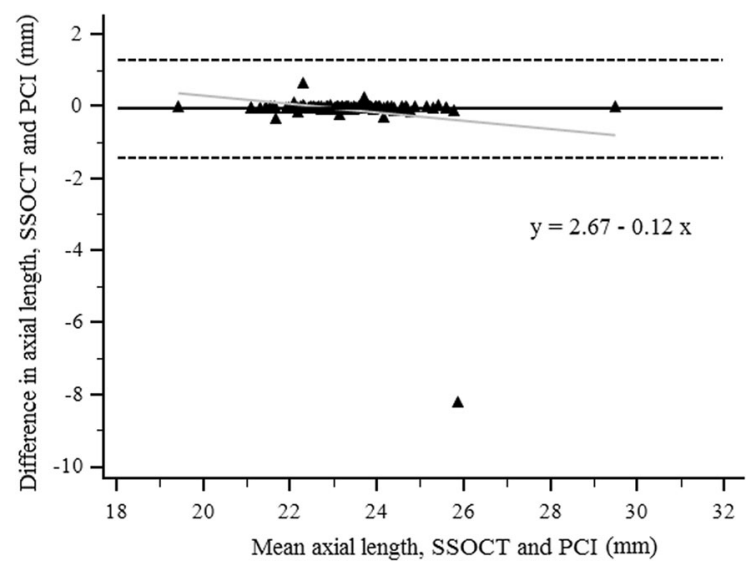

Fig. 3 Bland-Altman plots of the difference in axial length measurements between ANTERION (SSOCT) and IOLMaster (PCI) against their mean

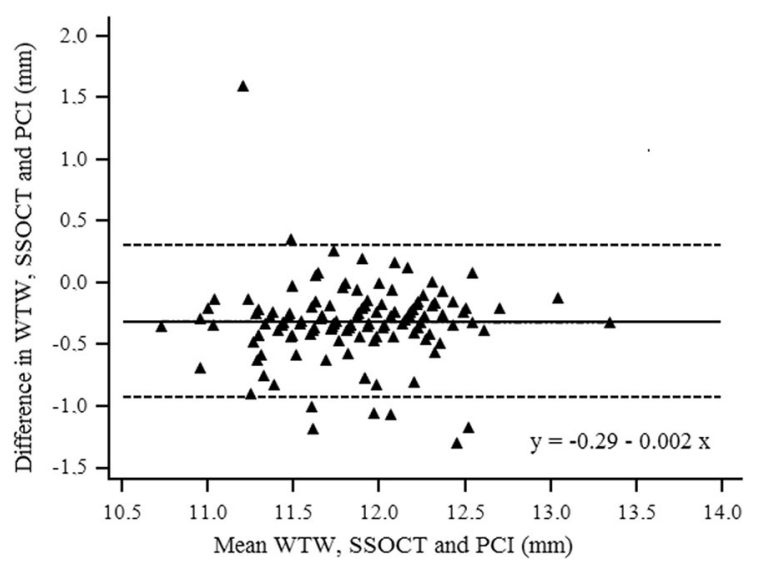

Fig. 4 Bland-Altman plots of the difference in white-to-white (WTW) measurements between ANTERION (SSOCT) and IOLMaster (PCI) against their mean

et al. reported no significant difference in average simulated keratometry value between PCI and another SSOCT device (Movu Argos) [11]. Total corneal subcapsular and dense nuclear cataract, IOLMaster was not able to measure AL. c Posterior subcapsular cataract, ANTERION was not able to identify posterior lens surface

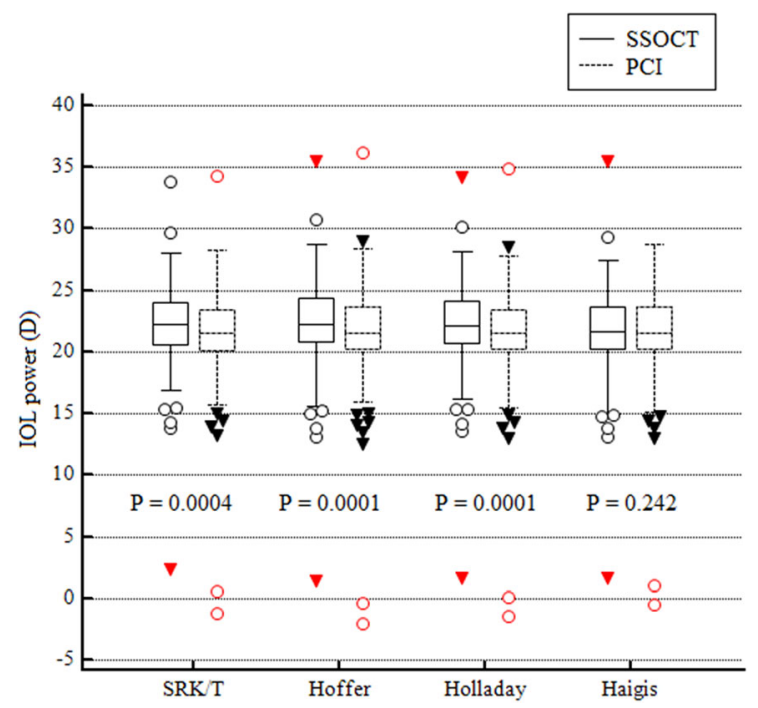

Fig. 5 Comparison of intraocular lens (IOL) power computed with four traditional calculation formulas using anterior simulated keratometry measured by ANTERION (SSOCT) and IOLMaster (PCI). The difference between their evaluations $(P$ value) was calculated with Student's $t$-test

power can be calculated from the anterior corneal radius and this estimation should theoretically be identical to the total corneal power measured by three dimensional tomographers [12]. Interestingly, poor correlation was observed both between simulated $\mathrm{Kf}$ and total $\mathrm{Kf}$ and between simulated $\mathrm{Ks}$ and total $\mathrm{Ks}$ measured with ANTERION in this study.

New SSOCT biometers are thought to be more often successful at evaluating axial length in opaque cataracts based on their optical principles [13]. In our study, AL measurements were successful in $95 \%$ of the cases both with SSOCT and PCI. Previous authors demonstrated high success rate of AL evaluation with different SSOCT devices ranging from 92.5 to $100 \%$ depending on the severity of lens opacities 
[11, 14-19]. In contrast to our findings, recent articles described a failure rate of PCI in measuring AL between 31 and $38 \%[19,20]$. In accordance with other authors [11, 17, 19, 21, 22], we did not observe a significant difference in $\mathrm{AL}$ values between SSOCT and PCI and ICC indicated good intra-device reproducibility for their measurements.

In cataract surgery, surgical outcome could be affected by the precise ACD measurements through the IOL power calculation and determination of the effective postoperative IOL position [23]. ACD is variously defined as the distance between the corneal epithelium and the anterior surface of the lens (external ACD), and as the distance between the corneal endothelium and the lens (internal ACD). $\mathrm{ACD}$ is measured along the visual axis from the corneal epithelium to the anterior crystalline lens by using IOLMaster 500, thus it includes the thickness of the cornea. ANTERION (Software Version 2.4.3) displays aqueous depth that is defined as the distance from the posterior corneal surface to the anterior lens surface. The external ACD could be calculated by adding the CCT to the AQD which might result in some sources of error. Consistent with the results of previous studies, ACD measured by a PCI device was deeper than that obtained by a SSOCT device but the difference was not statistically significant $[11,15,24]$. Yang et al. attributed this fundamental discrepancy in ACD measurements to the distinct imaging principles of PCI devices and SSOCTs [11]. Fisus et al. recently observed a mean absolute difference of $0.07 \pm 0.04 \mathrm{~mm}$ for ACD between the ANTERION and IOLMaster 700 [25].

Corneal diameter is important in determining the accurate size of phakic IOLs [26]. The IOLMaster evaluates the horizontal WTW distance automatically, the ANTERION offers a high resolution $16 \mathrm{~mm}$ WTW scan and computes the WTW value in the horizontal meridian. We observed a statistically significant difference in WTW measurements between PCI and SSOCT, but the intra-device consistency was acceptable. Agreeing with our previous study, PCI significantly overestimated WTW when compared to anterior segment OCT [26]. Other previous work concluded that WTW measurements with different devices suffer from significant inaccuracies [27, 28]. For anterior chamber angle supported IOL sizing, angle-to-angle distance would be more useful; this can be measured with OCT. For posterior chamber IOL sizing, most studies have used WTW plus $0.5 \mathrm{~mm}$ [29]; although sulcus-to-sulcus diameter would be more precise.

Another aim of this study was to investigate the impact of discrepancies between PCI and SSOCT on IOL calculation using different traditional formulas. All of these formulas are paraxial thin lens vergence formulae; they differ in the type of biometry parameters necessary to calculate IOL power [30]. Besides anterior axial curvature, total corneal power by ray tracing is also included in the ANTERION Cataract App. Savini et al. investigated the difference between total corneal power and simulated keratometry values provided by a Scheimpflug camera combined with Placido-disk topographer and their impact on accuracy of IOL power calculation [31]. They assumed that direct calculation of total corneal power (instead of estimation of simulated keratometry) might improve the accuracy of IOL power calculation [31]. Previous authors concluded that using total corneal power calculated with Pentacam did not result in significantly lower IOL prediction error [12,31]. We did not find a significant difference in computed IOL power using Haigis formula between IOLMaster and ANTERION. It should be noted that since the aim of this study was to compare the traditional PCI and the most recent swept source OCT biometer on a general population, the authors employed commonly used third-generation formulae, Holladay 1, SRK/T and Hoffer Q, as well as a fourth-generation formula, Haigis which requires ACD to estimate ELP [4-6]. The authors assume that the advantages of SSOCT in measuring total corneal power and lens thickness might be utilized better by using newer generation formulas in predicting IOL power more precisely.

In conclusion, our results implicated an overall good reproducibility of IOLMaster 500 and ANTERION in anterior keratometry, AL, ACD and WTW measurements. Both biometry devices had high success rate in evaluating axial length. The discrepancies between their measurements resulted in a significant difference in the calculated IOL power using SRK/T, Hoffer Q and Holladay 1 paraxial thin lens vergence formulas, but not for Haigis formula. Further studies are needed to investigate the repeatability and reliability performance of ANTERION SSOCT in biometry measurements. 
Author contribution ES contributed to investigation, data curation, methodology, formal analysis and writing-original draft; AC contributed to conceptualization, supervision, validation and writing - review and editing.

Funding Open access funding provided by University of Pécs. All authors certify that they have no affiliations with or involvement in any organization or entity with any financial interest (such as honoraria; educational grants; participation in speakers' bureaus; membership, employment, consultancies, stock ownership, or other equity interest; and expert testimony or patent-licensing arrangements), or non-financial interest (such as personal or professional relationships, affiliations, knowledge or beliefs) in the subject matter or materials discussed in this manuscript.

Data availability Data are available upon request.

\section{Declarations}

Conflict of interest The authors declare that they have no conflict of interest.

Ethical approval All procedures performed in studies involving human participants were in accordance with the ethical standards of the local Institutional Review Board and with the 1964 Helsinki declaration and its later amendments or comparable ethical standards.

Informed consent Since the study was retrospective in nature and we used deidentified patient information, the Review Board waived the need for written informed consent.

Open Access This article is licensed under a Creative Commons Attribution 4.0 International License, which permits use, sharing, adaptation, distribution and reproduction in any medium or format, as long as you give appropriate credit to the original author(s) and the source, provide a link to the Creative Commons licence, and indicate if changes were made. The images or other third party material in this article are included in the article's Creative Commons licence, unless indicated otherwise in a credit line to the material. If material is not included in the article's Creative Commons licence and your intended use is not permitted by statutory regulation or exceeds the permitted use, you will need to obtain permission directly from the copyright holder. To view a copy of this licence, visit http://creativecommons.org/licenses/by/4.0/.

\section{References}

1. Drexler W, Findl O, Menapace R, Rainer G, Vass C, Hitzenberger CK, Fercher AF (1998) Partial coherence interferometry: a novel approach to biometry in cataract surgery. Am J Ophthalmol 126:524-534. https://doi.org/10. 1016/s0002-9394(98)00113-5

2. Nemeth G, Modis L Jr (2019) Ocular measurements of a swept-source biometer: Repeatability data and comparison with an optical low-coherence interferometry biometer.
J Cataract Refract Surg 45:789-797. https://doi.org/10. 1016/j.jcrs.2018.12.018

3. Santodomingo-Rubido J, Mallen EA, Gilmartin B, Wolffsohn JS (2002) A new non-contact optical device for ocular biometry. Br J Ophthalmol 86:458-462. https://doi.org/10. 1136/bjo.86.4.458

4. Hoffer KJ (1993) The Hoffer Q formula: a comparison of theoretic and regression formulas. J Cataract Refract Surg 19:700-712. https://doi.org/10.1016/s08863350(13)80338-0

5. Holladay JT, Prager TC, Chandler TY, Musgrove KH, Lewis JW, Ruiz RS (1988) A three-part system for refining intraocular lens power calculations. J Cataract Refract Surg 14:17-24. https://doi.org/10.1016/s0886-3350(88)80059-2

6. Retzlaff JA, Sanders DR, Kraff MC (1990) Development of the SRK/T intraocular lens implant power calculation formula. J Cataract Refract Surg 16:333-340. https://doi.org/ 10.1016/s0886-3350(13)80705-5

7. Bland JM, Altman DG (1986) Statistical methods for assessing agreement between two methods of clinical measurement. Lancet 1:307-310

8. Bland JM, Altman DG (1999) Measuring agreement in method comparison studies. Stat Methods Med Res 8:135-160. https://doi.org/10.1177/096228029900800204

9. Choma M, Sarunic M, Yang C, Izatt J (2003) Sensitivity advantage of swept source and Fourier domain optical coherence tomography. Opt Express 11:2183-2189. https:// doi.org/10.1364/oe.11.002183

10. Szalai E, Németh G, Hassan Z, Módis L Jr (2017) Noncontact evaluation of corneal grafts: swept-source Fourier domain OCT versus high-resolution Scheimpflug imaging. Cornea 36:434-439. https://doi.org/10.1097/ICO. 0000000000001133

11. Yang CM, Lim DH, Kim HJ, Chung TY (2019) Comparison of two swept-source optical coherence tomography biometers and a partial coherence interferometer. PLoS ONE 14:e0223114. https://doi.org/10.1371/journal.pone. 0223114

12. Shammas HJ, Hoffer KJ, Shammas MC (2009) Scheimpflug photography keratometry readings for routine intraocular lens power calculation. J Cataract Refract Surg 35:330-334. https://doi.org/10.1016/j.jcrs.2008.10.041

13. Moshirfar M, Buckner B, Ronquillo YC, Hofstedt D (2019) Biometry in cataract surgery: a review of the current literature. Curr Opin Ophthalmol 30:9-12. https://doi.org/10. 1097/ICU.0000000000000536

14. Akman A, Asena L, Gungor SG (2016) Evaluation and comparison of the new swept source OCT-based IOLMaster 700 with the IOLMaster 500. Br J Ophthalmol 100:1201-1205. https://doi.org/10.1136/bjophthalmol2015-307779

15. Arriola-Villalobos P, Almendral-Gomez J, Garzon N, RuizMedrano J (2017) Agreement and clinical comparison between a new swept-source optical coherence tomography-based optical biometer and an optical low-coherence reflectometry biometer. Eye (Lond) 31:437-442. https://doi. org/10.1038/eye.2016.241

16. Kurian M, Negalur N, Das S, Puttaiah NK, Haria D, J TS, Thakkar MM, (2016) Biometry with a new swept-source optical coherence tomography biometer: Repeatability and 
agreement with an optical low-coherence reflectometry device. J Cataract Refract Surg 42(4):577-581

17. Shammas HJ, Ortiz S, Shammas MC, Kim SH, Chong C (2016) Biometry measurements using a new large coherence-length swept-source optical coherence tomographer. J Cataract Refract Surg 42:50-61. https://doi.org/10.1016/j. jcrs.2015.07.042

18. Huang J, Chen H, Li Y, Chen Z, Gao R, Yu J, Zhao Y, Lu W, McAlinden C, Wang Q (2019) Comprehensive Comparison of Axial Length Measurement With Three Swept-Source OCT-Based Biometers and Partial Coherence Interferometry. J Refract Surg 35:115-120. https://doi.org/10.3928/ 1081597X-20190109-01

19. Du YL, Wang G, Huang HC, Lin LY, Jin C, Liu LF, Liu XR, Zhang MZ (2019) Comparison of OA-2000 and IOL Master 500 using in cataract patients with high myopia. Int $\mathbf{J}$ Ophthalmol 12:844-847. https://doi.org/10.18240/ijo.2019. 05.23

20. McAlinden C, Wang Q, Pesudovs K, Yang X, Bao F, Yu A, Lin S, Feng Y, Huang J (2015) Axial length measurement failure rates with the IOLMaster and Lenstar LS 900 in eyes with cataract. PLoS ONE 10:e0128929. https://doi.org/10. 1371/journal.pone.0128929

21. Reitblat O, Levy A, Kleinmann G, Assia EI (2018) Accuracy of intraocular lens power calculation using three optical biometry measurement devices: the OA-2000, LenstarLS900 and IOLMaster-500. Eye (Lond) 32:1244-1252. https://doi.org/10.1038/s41433-018-0063-X

22. Schiano-Lomoriello D, Hoffer KJ, Abicca I, Savini G (2021) Repeatability of automated measurements by a new anterior segment optical coherence tomographer and biometer and agreement with standard devices. Sci Rep 11:983. https://doi.org/10.1038/s41598-020-79674-4

23. Olsen T, Corydon L, Gimbel H (1995) Intraocular lens power calculation with an improved anterior chamber depth prediction algorithm. J Cataract Refract Surg 21:313-319. https://doi.org/10.1016/s0886-3350(13)80140-X

24. Hoffer KJ, Hoffmann PC, Savini G (2016) Comparison of a new optical biometer using swept-source optical coherence tomography and a biometer using optical low-coherence reflectometry. J Cataract Refract Surg 42:1165-1172. https://doi.org/10.1016/j.jcrs.2016.07.013

25. Fiu AD, Hirnschall ND, Findl O (2020) Comparison of two swept-source optical coherence tomography-based biometry devices. J Cataract Refract Surg. https://doi.org/10.1097/ j.jcrs.0000000000000373 (in press)

26. Nemeth G, Hassan Z, Szalai E, Berta A, Modis L Jr (2010) Comparative analysis of white-to-white and angle-to-angle distance measurements with partial coherence interferometry and optical coherence tomography. J Cataract Refract Surg 36:1862-1866. https://doi.org/10.1016/j.jcrs.2010.05. 017

27. Pop M, Payette Y, Mansour M (2001) Predicting sulcus size using ocular measurements. J Cataract Refract Surg 27:1033-1038. https://doi.org/10.1016/s08863350(00)00830-0

28. Werner L, Izak AM, Pandey SK, Apple DJ, Trivedi RH, Schmidbauer JM (2004) Correlation between different measurements within the eye relative to phakic intraocular lens implantation. J Cataract Refract Surg 30:1982-1988. https://doi.org/10.1016/j.jcrs.2003.10.041

29. Zaldivar R, Ricur G, Oscherow S (2000) The phakic intraocular lens implant: in-depth focus on posterior chamber phakic IOLs. Curr Opin Ophthalmol 11:22-34. https://doi.org/10.1097/00055735-200002000-00005

30. Haigis W (2012) Challenges and approaches in modern biometry and IOL calculation. Saudi J Ophthalmol 26:7-12. https://doi.org/10.1016/j.sjopt.2011.11.007

31. Savini G, Hoffer KJ, Lomoriello DS, Ducoli P (2017) Simulated keratometry versus total corneal power by ray tracing. Cornea 36:1368-1372. https://doi.org/10.1097/ ICO.0000000000001343

Publisher's Note Springer Nature remains neutral with regard to jurisdictional claims in published maps and institutional affiliations. 